\title{
Integrated Municipal Service Application
}

\author{
Shubham Patil ${ }^{1}$, Shreekant Khadsan ${ }^{2}$, Saurabh Virkar ${ }^{3}$, Kartik Dhankude ${ }^{4}$, Mr Ramdas Jare ${ }^{5}$ \\ Student, Diploma in Computer Engineering, Pimpri Chinchwad Polytechnic, Pune, India ${ }^{1,2,3,4}$ \\ Lecturer, Diploma in Computer Engineering, Pimpri Chinchwad Polytechnic, Pune, India ${ }^{5}$
}

\begin{abstract}
In India, we have government bodies like Municipal Corporation responsible for maintaining cities. It is Municipal Corporation's responsibility to provide various services. It is their duty to address citizen's problems and give response to them. Whenever any citizen has to register complaint he/she has to visit municipal corporation. This is tedious and time-consuming process. It needs lot of paper work like writing letter with detailed information about problem. Due to emergence of internet many complaint sites are developed to provide citizens to lodge complaint in an online way. But today's generation tend use smart phones and mobile application instead of websites. So, considering current trends mobile application can be used instead of websites. Mobile application will not only be helpful to citizens but also make municipal corporation work feasible. Many features of smart phones like location sharing through GPS will be helpful to locate accurate area of problem.
\end{abstract}

Keywords: Mobile Application, Citizen, Municipal Corporation, Complaint, Online

\section{INTRODUCTION}

This paper focus on developing mobile application to provide citizens an easy way to register their complaints to the municipal corporations. This application will contain a problem solver provides an online way of solving the problems faced by the public by saving time and eradicate corruption. The objective of the problem solver is to make complaints easier to coordinate, monitor, track and resolve, and to provide an effective tool to identify and target problem areas and monitor complaints. Problem solver is used to record resolve and respond to customer complaints, requests as well as facilitate any other feedback.

\section{PROPOSED SYSTEM}

In this application citizen can register their complaints by submitting complaint details along with images and location which can be detected by GPS. To do so first user needs to be registered to this application. Once user is registered he/she has to login and then submit his/her grievances. Once the complaint is registered, an administrator finds it in the database and confirms that the complaint is real or not and also checks whether the complaint is repeated if so then administrator rejects that complaint. If the complaint is accepted, an administrator transfers that complaint to the intended municipal department. Administrator has the privilege to accept and reject the complaint and display the corresponding status to the applicant.

\section{A. Modules}

Project will be divided into three parts

- $\quad$ Android User Interface.

- $\quad$ MySQL will work as database.

- Java code will be used for validation and processing of user input and database. It will act as a middle layer.

B. Working Module

- User Complaint

Whenever user see some problems around itself like garbage overflowing, drainage leakage, traffic issues, burglar etc. he/she can take picture and add some description about the situation. Once complaint is made municipality admin can view the complaint. When complaint will be raised it will be in CREATE lifecycle.

\section{- $\quad$ Administrator View}

Administrator can view the complaints raised by the users and will provide the updates depending on the work done. Admin will promote the problems to IN WORK status whenever problem solving is started. Once problem is solved admin will promote it to complete stage.

- $\quad$ Closed Lifecycle

The person who has raised the complaint can only close the lifecycle of the complaint. 


\section{IJARCCE}

A. About Existing System

- $\quad$ Person must go to municipality for his complaints.

- $\quad$ All the arrived Complaints are submitted to the Administrator.

- $\quad$ Administrators distribute complaints among different departments according to complaint type.

- $\quad$ Employees solve the complaints and note the complaint status in books manually.

- $\quad$ Dispatch officer check the books and reply the solved complaints.

- Inquiry officer gives the current status information of complaints from the books.

B. Limitations of Existing System

- Possibility of loss complaint Record.

- All complaints handled manually. So, there is possibility to loss of complaints record because of transferring Complaints record between different physical levels and also inattention of employees.

- There is no proper management procedure for a complaint inquiry for people.

- Lots of paper work: For single complaints, many documents are need to be created.

\section{SCOPE OF THE PROJECT}

- Problem Solver provides services for arrived Complaint of people to municipality.

- People can know the currently processing status of their Complaints.

- All the complaints arrived from people are distributed to the different departments according to Complaint category.

- Administrator can see all Complaints and Individual Department Complaints.

\section{ARCHITECTURAL MODEL}

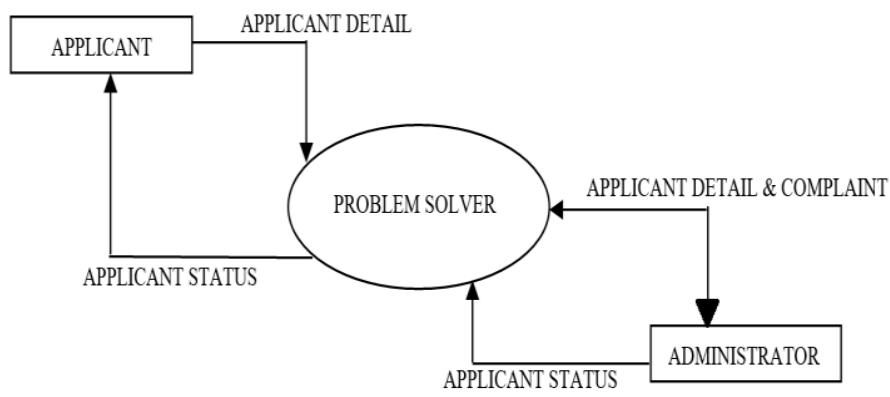

- Applicant: Applicant is any citizen who tends to register complaint. Applicant has to first register himself then login. Applicant is common person who shares location and problem to municipal corporation via GPS. Applicant will able to see their complaint status.

- Problem Solver: Problem solver provides an online way of solving the problems. It acts as a mediator between Applicant and Administrator. Problem solver will display the status to applicant provided by the Administrator.

- Administrator: Administrator has to login with its login Id. Administrator manages all the server related activities. Administrator receives complaint details from Problem solver and sends back the complaint status.

\section{TECHNICAL REQUIREMENT}

A. Hardware Requirements

- Intel processor

- $\quad$ Minimum 3 GB RAM, plus 1GB for Android Emulator

- $\quad$ Minimum $2 \mathrm{~GB}$ of available disk space

- $\quad 1280$ x 800 minimum screen resolution

B. Software Requirements

- Windows (XP or later) OS

- $\quad$ jdk 1.7

- $\quad$ Android Studio

- $\quad$ MySQL 5.5 


\section{ADVANTAGES OF THE PROJECT}

- $\quad$ Easy to access

- $\quad$ Fast to solve the problem and fast management

- $\quad$ Automation

- $\quad$ Saves time by avoiding paper work

- Status of complaints is visible

\section{CONCLUSION}

We proposed and introduced a mobile application for citizens to register complaints against the problems they're facing which can be solved by municipal corporations. As nowadays mobile phones are much used by people so we can use an app which can be helpful for citizens to lodge a complaint in a very simple way by uploading a picture of suspected place and use GPS to provide the location of that place into respective Municipal Corporations. Indirectly this application can also benefit municipal corporations by smoothening their work. This application also will eliminate corruption as common people will directly communicate with governing bodies without personally meeting them. It will help improve performance of municipal corporations.

\section{REFERENCES}

[1]. B.Y. Ricardo and R.N. Berthier, Modern Information Retrieval. Addison Wesley Longman, 1999

[2]. H. Kim, P. Howland, And H. Park, "Dimension Reduction In Text classification With Support Vector Machines," J. Machine Learning Research, Vol. 6, Pp. 37-53, 2005.

[3]. R. Kohavi And G. John, "Wrappers For Feature Subset Selection,” Artificial Intelligence, Vol. 97, No. 1-2, Pp. 273-324, 1997.

[4]. Patrícia Abreu, Sérgio Sousa, Member, IAENG, and Isabel Lopes, "Using Six Sigma to Improve Complaints Handling", Proceedings of the World Congress on Engineering 2012 Vol IIIWCE 2012, July 4 - 6, 2012, London

[5]. R. Johnston, "Linking complaint management to profit," International Journal of Service Industry Management, vol. 12, pp. 60-69,2001.

[6]. V. Bosch and F. Enriquez, "TQM and QFD: exploiting a customer complaint management system," International Journal of Quality and Reliability Management, vol. 22, pp. 30-37,2005. 